\title{
Comfort model for automobile seat
}

\author{
Lizandra da Silva a, ${ }^{a}$, Silvana Ligia Vincenzi Bortolotti ${ }^{b}$, Izabel Carolina Martins Campos ${ }^{\text {a,c }}$ and \\ Eugenio Andrés Díaz Merino ${ }^{a}$ \\ ${ }^{a}$ Federal University of Santa Catarina - UFSC, SC, Brazil. \\ ${ }^{b}$ Technological Federal University of Paraná - UTFPR, PR, Brazil. \\ 'State Secretary of Administration's Office
}

\begin{abstract}
Comfort on automobile seats is lived daily by thousands of drivers. Epistemologically, comfort can be understood under the theory of complexity, since it emerges from a chain of interrelationships between man and several elements of the system. This interaction process can engender extreme comfort associated to the feeling of pleasure and wellbeing or, on the other hand, lead to discomfort, normally followed by pain. This article has for purpose the development of a theoretical model that favours the comfort feature on automobile seats through the identification of its facets and indicators. For such, a theoretical study is resorted to, allowing the mapping of elements that constitute the model. The results present a comfort model on automobile seats that contemplates the (physical, psychological, object, context and environment) facets. This model is expected to contribute with the automobile industry for the development of improvements of the ergonomic project of seats to increase the comfort noticed by the users.
\end{abstract}

Keywords: comfort, ergonomics, automobile, seat, model

\section{Introduction}

The automobile seat represents a workspace that should provide the occupier adequate positioning so he can perform his driving task while attending several safety criteria while also being acceptable regarding the driver's need for comfort [23]. Comfort is considered such an important feature on the automobile seat [9] that automotive industries use them to distinguish their products from those of their competitors [17].

Comfort is defined as a convenience or wellbeing experienced by the final user while using a product or just after using it [36]. In contrast, discomfort is related to experiencing pain and the feeling of weight. [38] which comes man and his physiological, psychological wellbeing or all together, are assessed in the wrong [31].

A product cannot be regarded as comfortable in itself, but it becomes comfortable (or uncomfortable) when it is used, when it goes through the person's perception about the experience undergone. In this matter, the user will decide whether a product is comfortable or not or if it leads to discomfort. This complicates the creation of comfort because it is not known how each individual will react to a product [37].

It is not impossible to project a comfortable automobile seat, but for that it is necessary to consider aspects that influence the driver's experience of comfort. To promote the maximum comfort the proposition of explanatory models is necessary, making known what is unobservable, giving ergonomics scientific status [5].

In this regard, the article means to develop a theoretical model of comfort on automobile seats, allowing a performance of the phenomenon with the identification of facets and indicators, main elements influencing the driver's perception of comfort.

\subsection{Comfort on automobile seat}

Thousands of people daily realise the comfort or discomfort on their automobile seat, especially drivers who work for long hours. Comfort on automobile seat is a multifaceted phenomenon and its mapping contributes to making it understood $[21,12]$.

Corresponding Author. Campus Universitário - Trindade - Fpolis - SC - Brasil. Cx Postal 476. CEP 88040900. Tel. +55 48 37217104; Fax: +55 48 37217032; Email: lizandrafisio@deps.ufsc.br. 
According to Kolich [21], comfort on automobile seats contemplates four factors, or facets, which interfere with the perception of comfort: vehicle/package, social, individual and the seat, according to Figure 1. The indicators of the vehicle/package factor are: seat height, the vision field, pedals, direction, tyres position, head, space for the knees and kind of transmission. Thus, the individual can differently perceive comfort on a single seat when placed in a different package of vehicle.

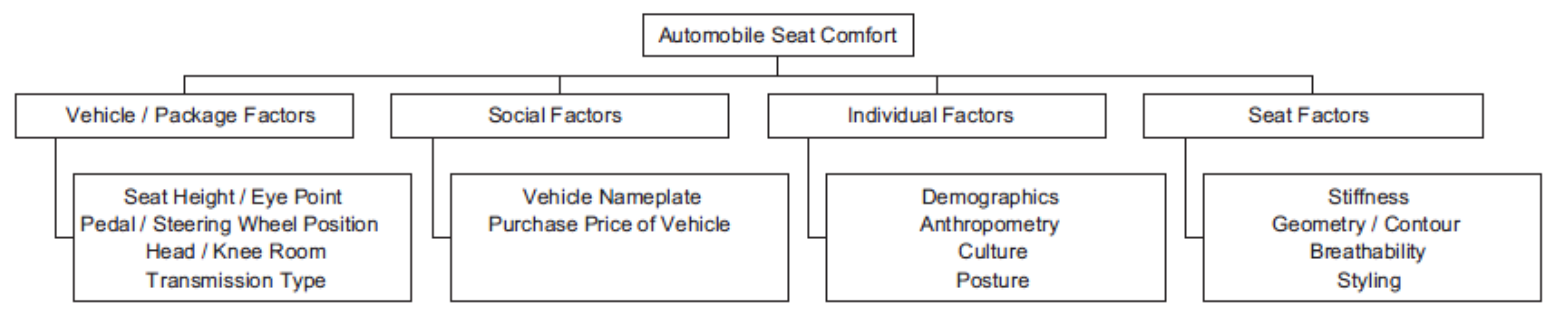

Fig. 1. Factors affecting subjective perceptions of automobile seat comfort. Source: [17].

The social factors or facets include the car plates and the purchase price of the vehicle. The individual factors contemplate the indicators: demography, anthropometrics, culture and posture. The culture has been identified with the western Europeans who, in relation to North Americans, prefer firmer seats. The seat factor involves: rigidity, geometry, shape, breathability and style. Besides these, the author presents other factors also interfering with the subjective perception of comfort in automobile seats: noise, temperature, panel of instruments and control panel and storage [21].

The individual facet of comfort on automobile seat is exploited on literature by means of several indicators: posture [29, 3, 28, 21, 17, 12], anthropometrics $[29,21,22,23,24,7,12]$, demography [24, 23, 21, 12], fatigue $[17,11]$, distribution of pressure on the seat $[29,9,24,23,25,17]$, physiological degradation [11], muscle activity [17], body region [14, 7], contracture [14] and age [12].

The identification of posture is difficult because people with the same body dimensions can assume body completely different positions [12]. Inadequate position of the foot is an indicator for the development of callous on the foot plant of the heel with the vehicle driving [28].

Among the advantages of working in the seating position, Iida [18] highlights: it uses less energy in relation to the standing position reducing the fatigue; it diminishes the mechanical pressure on the lower limbs; it reduces the hydrostatic pressure on the lower limbs decreasing the demands over the heart; it reduces the hydrostatic pressure on the lower limbs with a decrease of demands on the heart; it makes it easier to have a work reference point; it allows the simultaneous use of hands and feet (pedals). On the other hand, the seating position prompts disadvantages such as: increased pressure on the buttocks and sciatic tuberosity; restriction of reach and diminished blood circulation on the inferior limbs.

The seated position in combination with other indicators, such as whole body and/or posture vibration, leads to an increased risk of lumbago. However, the influence of the length of exposure to vibration seems to be more important than the magnitude of the exposure, suggesting a cumulative effect. Still, the prevalence rate of lumbago where the worker is required to stay seated most of the working time is significantly superior to the prevalence rate for the population in general [3].

The prolonged seating significantly increases the risk of lumbago, especially when associated to vibration in body parts and awkward postures. The sole fact of being seated probably doesn't represent a risk until the person is exposed, to a certain level of vibration and a forced posture. Thus, when the risk factors are combined, the risk of lumbago increases [3].

Forced postures constitute an aggravating condition for the health of the taxi driver. The causes of forced posture can be: high number of hours in the seated position, adoption of compensatory postures for the promotion of comfort, ill adjusted seat and mirrors or insufficient space on the driver workstation stopping him from varying leg position [27].

Comfortable accommodation for the lumbar area can be achieved by means of seat adjustment [12]. To allow variations of posture to alleviate the pressure on the inter-vertebral disks and muscle tension. The movable back of the seat allows the user to recline periodically, in order to avoid fatigue [18].

The existence of several seat adjustments (back inclination, horizontal seat positioning, etc.) offer sup- 
port to the driver's back leading to the presence or absence of lumbar support; as well as the kind of upholstery (i.e., canvas versus vinyl). These indicators can affect the muscle activation: the shear force between soft tissues and this does not affect only the driver's perception of comfort but also his feeling of fatigue [16].

The muscle activity at its maximum contributes for the perception of comfort, for if force on the volunteer muscles (those controlled by central nervous system) needed for keeping a seated posture, are elevated, there will straightaway be an increased perception of discomfort [17]. That physiological degradation and fatigue can reduce the driver's performance on automobiles. The evolution of fatigue, discomfort and performance rates of people seated in two different kinds of car seats, with and without vibration, have pointed out that the performance was reduced when individuals were on an uncomfortable seat with vibration, making clear the evolution of discomfort [11].

One of the most common approaches developed on automobile seats is based on the measurement of pressure on the interface seat/man $[29,9,24,23,25$, 17]. This kind of technology, generally through tactile sensors, enables a variety of experiences to be accomplished in real time.

A greater uniformity on the distribution of pressure and a lower peak of pressure, and a wider and more symmetric contact surface imply an improvement of comfort on the seat. The shear stress from the contact contributes for the perception of seat discomfort by individuals who spend a lengthy time in the seating position, because it brings damage to the soft tissues and can lead to the formation of ulcers or tissue necrosis [17].

The comfort parameters mostly mentioned in the literature are: seat/man rate of contact pressure; highest seat/man contact pressure; size of the seat/man contact area and extent of the of the seat/man contact area symmetry. All these parameters quantifying comfort are based on measurements for the distribution of seat/man contact pressure on contact areas [16].

Kolich and Tabourn [24] have developed and validated a step-by-step to find a global index of subjective comfort, grounded on the characteristics of pressure on the seat interface, the passengers' anthropometrics, the passengers' demography and percept of the seat appearance. Such study has found the connection between the objective measurements and the subjective perceptions of comfort, pointing out that the pressure on the seat interface can be used to distinguish the seats. .

Research by Kyung; Nussbaum; Babski-Reeves [25] has identified that the pressure on the seat/man interface has been more related to comfort than discomfort and they support the following recommendations for the car seat projects: (1) lower rates of pressure on the buttocks and higher on the back, and (2) balanced pressure among buttocks, upper part and lower part of the body.

Research by Ebe e Griffin [9] has identified that the seat samples that created less pressure were those related to a higher comfort rate than those with higher total pressure. This study brought the conclusion that pressure under the ischiatic tuberosity can reflect on comfort factors or facets.

As for the mentioned discomfort on body parts, Grabisch et al [14] have assessed drivers perception concluding that the most significant types of discomfort were: super-heating, contraction and points of stiffness. Thus when a single discomfort such as superheating, contraction or point of stiffness appears, that is enough for a general discomfort to be felt. The body areas that prevailed in this study were: upper part of the back and arms. For Daruis, Deros and Noor [7] the spine was mentioned as the part of the body felt with more intensity in $60 \%$ of the cases, followed by the neck (56\%) and lower back (44\%).

Another individual indicator of discomfort is the anthropometrics, science studying the measurements of the human body dimensions. It makes knowing the space volume possible and the possibility of reaching a goal through movement. Anthropometric measurements are the starting point for concretely dimensioning products, exposed to work environments that are suitable to the worker [1]. However, anthropometric criteria alone don't guarantee comfortable automobile seats. Kolich [22] has studied comfort on automobile seats through the preference of individuals in relation with anthropometric data. In this context, 12 people evaluated 5 different seats on compact car over short periods of time. The characteristics of the seats were compared to the subjective answers and discrepancies have been found between the anthropometric criteria and the preferred lumbar height, seat width, cushion length and width.

The comfort factor, or facet, that relate to the automobile seat is explored in the literature by the following indicators: height $[25,12]$, adjustment $[12,17$, 29], position [23], properties of the upholstered seat such as width, length and shape [17, 22, 29], foam density and softness [9], durability [9, 12] and aesthetics $[23,24]$. 
Rigidity, geometry, outline, breathability and style are considered seat indicators. Rigidity refers to the seat system resistance. Geometry defines the seat shape in terms of width, length and height, whereas the shape defines the profile of the seatting surface (i.e., placement and prominence of the lumbar height). The seat geometry and shape should accommodate the anthropometric variability of the targetpopulation. Breathability relates to a soft finishing (or rather the foam density and the upholstery material structure), and it can affect comfort on the automobile seat when in extreme environmental conditions. The style must be regarded as a seat indicator of aesthetic quality because it can affect the perception of comfort [12].

The study by Ebe and Griffin [9] has pointed out that low foam hardness is more comfortable than high stiffness, but the relation between stiffness and comfort in the seat have not been linear. This indicates that the comfort rate is affected by two indicators: the feeling of being accommodated while seating and the feeling of the foam hardness.

For Reed, Schneider and Ricci [29], the project parameters of automobile seats focused on comfort are divided into three categories interacting among themselves, such as, for example: a change on the back curvature (support) will affect the distribution of pressure (sensation) and also change the length of the effective cushioning (adjustment). The three categories described in this study are: 1) Adjustment parameters, established through the anthropometrics of the population of passengers and it includes measures such as the length of the seat cushion. 2) Parameters of sensation reported from the physical contact between the occupant and the seat. These are a combination of subjective and objective measurements, such as, for example, the distribution of pressure and the upholstery features. 3) Parameters of support, affecting the occupier's posture and include the seat shape to its settings.

The environmental factors, or facets, affecting the perception of comfort in the automobile seat are indicated by: vibration $[11,3,9,10,34,7,14]$, noise [21, $12,7,14]$, temperature $[21,12,14]$ and quality of air [12].

Noise and vibration affect the general discomfort on the seat [34], however, for Dauris, Deros and Noor [7] discomfort on the seat is more affected by vibration. The driver and the passengers are exposed to vibration directly associated to the characteristics of the vehicle (i.e., pedals and steering wheel transmit vibrations to the driver's hands and feet) and road surface. Some of these vibrations are transmitted to the occupants' buttocks and back along the vertebral axis through the seat basis and backrest. A Combination of those vibrations will generate discomfort, especially during long journeys [11].

Among the causes of vibration that contribute to putting the taxi drivers' health at risk, the Ministry of Labour and Immigration in Spain [27] mentions the vehicle's dampening system, the vibration transmitted throught the seat and its bad conservation state. The consequences of continual exposure to vibration transmitted to the body can affect the digestive system (ulcers), spine and bones. However, the regular maintenance of the damping system in the vehicle, an adequate car seat suitable to the size of the body and in good conservation state could diminish the exposure to vibration.

Ebe and Griffin [10] have proposed the static (rigidity) and dynamic (vibration) characteristics of the seat can both influence the perception of comfort. The importance of separating the characteristics, static from dynamic, depend on another variable, for example when the vibration amplitude is low, the discomfort assessment is dominated by the static characteristics of the seat. As vibration increases, the assessment of discomfort is influenced by vibration more. For that reason it is important to take into account the characteristics of static as much as the dynamic characteristics to predict discomfort. However, such measures are not always correlated to the assessment of comfort, especially when the magnitude of vibration is reduced. With low vibration, the seat rigidity can have a dominant influence over the seat comfort.

On an investigation over discomfort with Malaysian car drivers, Daruis, Deros and Noor [7] have found that men and women noticed discomfort caused by noise, vibration and the seat, but with different levels of sensibility. The men have noticed more discomfort from noise, whereas women notice more from vibration, however there was no significant difference between the sexes regarding discomfort in general. According to the results of the study of Grabisch et al [14] the type of vibration was insignificant for the kind of discomfort, with the conclusion that there are more discrepancies on the analysis based on macro-zones of the body than on the kinds of discomfort.

The factors, or facets, of the context, interfere with the perception of comfort, thus, the seat can be the same, but the conditions of its use affect the subjective perception of comfort. The indicators of this facet listed on the literature are: time [24, 21], culture 
[24], work activity $[37,32]$ and social indicators [30, $12,21]$.

The perception of comfort can be affected in terms of time $[26,3,14,4,17,27]$, thus the seat of a taxi vehicle can be regarded more or less comfortable on a longer journey or on a short traject.

For Kolich and Tabourn [24] the perception of comfort can be different in several parts of the world. West Europeans prefer firmer seats when compared to North Americans [21]. In the Brazilian context, for example, the automotive seat can be noticed as more or less comfortable in different parts of the country, considering the cultural aspects of those country regions.

The work activity, also mentioned by [2, 6, 32, 15], interferes with the perception of comfort because when the seat is not suitable to the activity demands it will no longer be ergonomic and, consequently, it will be uncomfortable. In this regard, some authors $[36,32]$ suggest that the comfort is analysed at the light of activity within the systems of work.

As for the social indicators, Kolich [21] and Fazlollahtabar [12] consider the vehicle package as one of the main determinants of comfort on an automobile seat, defined by space (for the legs, shoulders and hips). The same seat, when placed in different automobile packages, receives different comfort assessments, just as when they are sold with different number plates and (purchase) price [12].

\section{Method}

This paper is a conceptual theoretical study, which results in the refinement of existing theory about comfort in automobile seat. The methodological procedure used for the construction of the automobile seat comfort model have the purpose of guaranteeing the quality of the information establishing it. The process for the development of the model was made of three phases: 1) Definition of the construct from literature review; 2) Preparation of the table for the identification of the facets and indicators; 3) Visual representation of comfort on automobile seats (conceptual model).

For the literature review was performed a selection of articles in the databases (Capes, Scielo, EBSCO and Science Direct Online); in addition some books not available in these databases. The periodic consultation considered the following keywords: "vehicle seat comfort", "automobile seat comfort", "automotive seat comfort" and "sitting comfort". All abstracts has analysed and only those who have provided relevant content for this study were selected.

After the analysis of selected studies, was development a table witch specification of facets and indicators of automobile seat comfort according to contributions from other research. Finally, it was developed a graphical representation of the automotive seat comfort model which aims to present the phenomenon as a complex network of interrelationships between facets and indicators.

\section{Results}

Among the studies selected, 68\% (26) were periodicals and $32 \%$ (12) from of the thesis and books. By means of a literature review it has been possible to elaborate a table for the identification of the facets and indicators that form comfort on automobile seats, according to Table 1.

From this table, a theoretical model is proposed for comfort on automobile seat, according to Figure 2, where comfort rises from a net interaction between the facets (psychological, physical, object, context and environment) and their respective indicators.

The physical facet corresponds to the physical aspects of man that affect the perception of comfort.

The Psychological Facet comprehends the characteristics influence the way in which a person understands, acts and feels the world around them; it interferes with their operating mode, strategies they use at work, future actions and perception of comfort.

The Object Facet refers to the characteristics of the automobile seat, considering its integrating parts: seat and backrest.

The Environmental Facet concerns the aspects of the environment influencing the perception of comfort.

The Context Facet corresponds to a set of circumstances influencing the event, or the characteristics of the situation in which a certain phenomenon happens. Such facet is made up of time, culture, and social activity indicators. 
Table 1

Table with the specification of facets and indicators of comfort on automobile seats.

\begin{tabular}{|c|c|}
\hline \multicolumn{2}{|c|}{ PHYSICAL FACET } \\
\hline Indicators & Studies identifying these indicators \\
\hline Distribution of pressure on the seat & {$[29,9,24,23,17]$} \\
\hline Anthropometric measurements & {$[29,24,23,22,21,7]$} \\
\hline Fatigue & {$[17,11]$} \\
\hline Muscle contracture & {$[14]$} \\
\hline Pain on different body regions & {$[7,14]$} \\
\hline Formication/Numbness & [30] \\
\hline Relaxed & {$[38,26,35,13]$} \\
\hline Weight & [38] \\
\hline Movements & [4] \\
\hline Posture & {$[29,17,21,3,12,28]$} \\
\hline \multicolumn{2}{|c|}{ PSYCOLOGICAL FACET } \\
\hline Indicators & Studies identifying these indicators \\
\hline Wellbeing & {$[38,26,4,13]$} \\
\hline Discomfort & [35] \\
\hline Joy,calm & {$[38,13]$} \\
\hline Deception, annoyance & [8] \\
\hline Pleasure & {$[38,26,35,8,25,19]$} \\
\hline Satisfaction & {$[38,13,8]$} \\
\hline Tranquil & {$[38,13]$} \\
\hline Liking, irritability & {$[35,4]$} \\
\hline \multicolumn{2}{|c|}{ OBJECT FACET } \\
\hline Indicators & Studies identifying these indicators \\
\hline Safety, luxurious, spacious & {$[38,13]$} \\
\hline Pleasant & {$[38,13,8,33]$} \\
\hline Cosy & {$[38,35]$} \\
\hline Aesthetics & {$[24,23,26]$,} \\
\hline Breathability & [21] \\
\hline Adjustment & {$[29,12,18,16]$} \\
\hline Density & [9] \\
\hline Firmness & {$[24,34]$} \\
\hline Softness & {$[9,16]$} \\
\hline Durability & {$[12,9,16]$} \\
\hline Shape & {$[29,22,21,34]$} \\
\hline Support & {$[29,24,38,13,16,34]$} \\
\hline Height & {$[21,12,34]$} \\
\hline Length & {$[29,22,16]$} \\
\hline Width & {$[22,12,16,34]$} \\
\hline \multicolumn{2}{|c|}{ ENVIRONMENTAL FACET } \\
\hline Indicators & Studies identifying these indicators \\
\hline Noise & {$[21,7,14,12]$} \\
\hline Temperature & {$[21,14,12]$} \\
\hline Vibration & {$[9,7,11,14,3,34]$} \\
\hline \multicolumn{2}{|c|}{ CONTEXT FACET } \\
\hline Indicators & Studies identifying these indicators \\
\hline Time & {$[24,14,26,4,3,20,4]$} \\
\hline Culture & [24] \\
\hline Work Activity & {$[36,37,32]$} \\
\hline Social Indicators & {$[21,30,12]$} \\
\hline
\end{tabular}

The complexity of comfort does not imply understanding it completely but, on the other hand, it stimulates the consideration of questions that help understanding it. The identification of the facets with their respective indicators, through the model, contributes for the Scientific Ergonomics when it explains how the interaction process between man-seat happens during the performance of the automobile driving activity. 
Facet of the context: time, work activity social indicators, culture.

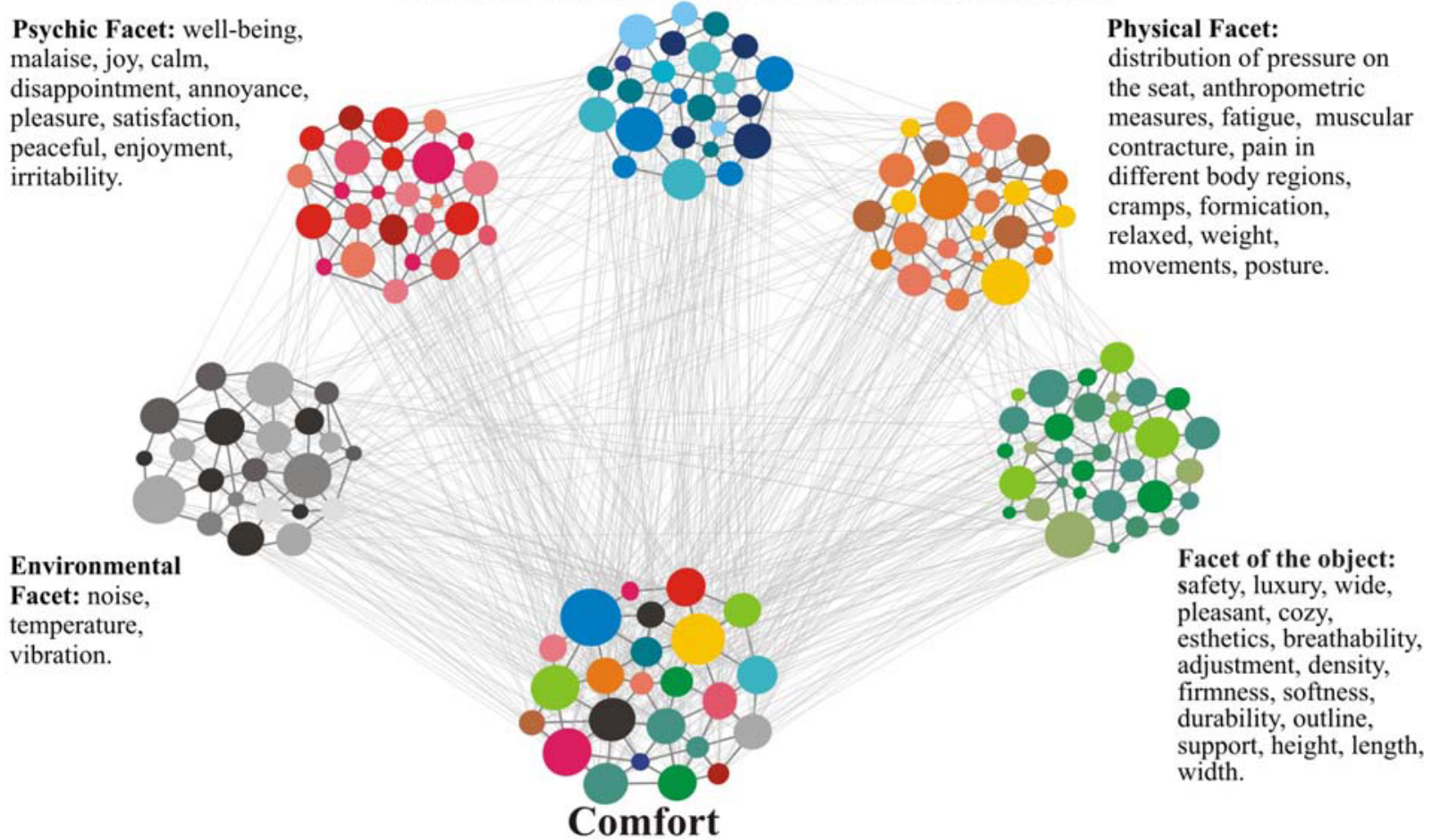

Fig. 2. Proposition of a comfort model for automobile seats.

\section{Conclusions}

Although it is the target of the automotive industry to sell the promotion of comfort, the literature highlights that their focus is still the absence of discomfort. The model presented on this research allows the identification of facets and indicators that interfere with the perception of comfort on automobile seats.

However, the evaluation of comfort, in a broader sense, must comprise the interaction between indicators of these facets. That can be achieved through direct (objective) or indirect (subjective) measures, but only the indirect have been the object of this research.

\section{References}

[1] J. Abrahão, et al, Introdução à ergonomia: da prática à teoria, Blucher, São Paulo, 2009.

[2] J. Annett, Subjective rating scales: science or art?, Ergonomics 45, 14 (2002) 966-987.
[3] K. M. Black, A. Lis and M. Nordin, Association between sitting and occupation low back pain, Ação Ergonômica 1, 3 (2002) 73-86.

[4] B. A. Crane, M. B. Holm, D. Hobson, Development of a Wheelchair Seating Discomfort Assessment Tool. In: Proceedings of the 19th International Seating Symposium,

[5] 2.00Brie, Condições da pesquisa científica em ergonomia, in: $A$ ergonomia em busca dos seus princípios: debates epistemológicos, F. Daniellou, Edgard Blucher, São Paulo,

[6] BO.0H. Dainoff, et al, Forget About Aesthetics in Chair Design: Ergonomics Should Provide the Basis for Comfort, in: Ergonomics and Health Aspects, M. J. Dainoff, (Ed), Heedelberg, Berlin, 2007, pp. 19-25.

[7] D. D. I. Dauris, B. M. D. Deros and M. J. M. Noor, Understanding the effect of noise, vibration and seat discomfort towards a passenger's vehicle driver through self-reported survey, Journal Teknologic 49 (2008) 39-53.

[8] P. M. A. Desmet, P. Hekkert; J.J. Jacobs, When a car makes you smile: Development and application of an instrument to measure product emotions, in: Advances in Consumer Research, S. J. Hoch, R. J. Meyer, 2000, pp. 111-117.

[9] K, Ebe and M. J. Griffin, Factors affecting static seat comfort, Ergonomics 44 (2001) 901-921.

[10]K, Ebe and M. J. Griffin, Quantitative prediction of overall seat discomfort, Ergonomics 43 (2000) 791-806.

[11]W. E. Falou, et al, Evaluation of driver discomfort during long-duration car driving, Applied Ergonomics 34 (2003) 249-255. 
[12]H. Fazlollahtabar, A subjective framework for seat comfort based on a heuristic multi criteria decision making technique and anthropometry, Applied Ergonomics, $\mathbf{x x x}$ (2010) 1-13.

[13] R. S. Goonetilleke, Comfort-Discomfort Phase Change, in: International Encyclopedia of Ergonomics and Human Factors, 2th ed, 3th vol, CRC press, London, 2006.

[14]M. Grabish, et al, Subjective Evaluation of Discomfort in Sitting Positions, Fuzzy optimization and Decision Making, 1 (2002) 287-312.

[15]L. Groenesteijn, et al, Effects of differences in Office chair controls, seat and backrest angle design in relation to tasks, Applied ergonomics 40 (2009) 362-370.

[16]M. Grujicic, et al, Musculoskeletal computational analysis of the influence of car-seat design/adjustments on long-distance driving fatigue, International Journal of Industrial Ergonomics, 40 (2010) 345-355.

[17]M. Grujicic, et al, Seat-cushion and soft-tissue material modeling and a finite element investigation of the seating comfort for passenger-vehicle occupants, Materials and Design 30 (2009) 4273-4285.

[18]I. Iida, Ergonomia: Projeto e Produção, Ed. Edgard Blucher, São Paulo, 2005.

[19] P. W. Jordan, Designing Pleasurable Products: an introduction to the new human factors, Taylor and Francis, London, 2000.

[20] D. Kee, W. Karwowski, The boundaries for joint angles of isocomfort for sitting and standing males based on perceived comfort of static joint postures, Ergonomics 44, 6 (2001) 614 648.

[21] M. Kolich, A conceptual framework proposed to formalize the scientific investigation of automobile seat comfort, Applied Ergonomics 39 (2008) 15-27.

[22] M. Kolich, Automobile seat comfort: occupant preferences vs. anthropometric accommodation, Applied Ergonomics, 34, (2003) 177-184.

[23] M. Kolich, Predicting automobile seat comfort using a neural network, International Journal of Industrial Ergonomics 33 (2004) 285-293.

[24] M. Kolich and S. Taboun, Ergonomics modelling and evaluation of automobile seat comfort, Ergonomics 47, 8 (2004) 841 -863 .

[25] G. Kyung and M. A. Nussbaum, Driver sitting comfort and discomfort (part II): Relationships with and prediction from interface pressure, International Journal of Industrial Ergonomics 38 (2008) 526-538.

[26] G. Martin, L. Helander, L. Zhang, Field studies of comfort and discomfort in sitting, Ergonomics 40, 9 (1997) 895-91.

[27] Ministerio del Trabajo e Immigráccion. Guía Práctica de Riesgos y Medidas Preventivas para Autónomos em El Sector Del Taxi. Gobierno da España.

[28]B. Rajput and R. J. Abboud, The inadequate effect of automobile seating on foot posture and callus development, Ergonomics 50 (2007) 131-137.

[29] M. P. Reed, L. W. Schneider and L. L. Ricci, Survey of auto seat design recommendations for improved comfort, Michigan: University of Michigan, 1994.

[30] S. L. Sauter et al, Musculoskeletal Discomfort Surveys Used at NIOSH, in: Handbook of Human Factors and Ergonomics Methods, CRC Press, London, 2005.

[31]W. Shen and K. C. Parsons, Validity and reability of rating scales for seated pressure distribution, International Journal of Industrial Ergonomics 20 (1997) 441-461.

[32]L. da S. Silveira, E. A. D. Merino, R. M. Cruz. Projeto ergonômico de produtos com ênfase no conforto. In: Anais do $9^{\circ}$. Ergodesign; 2009 Set; Curitiba: Paraná; 2009. 1. CD-ROM

[33] K. Slater, Human Comfort, Thomas Books, USA, 1985.

[34]D. R. Smith, D. M. Andrews and P. T. Wawrow, Development and evaluation of the Automotive Seating Discomfort Questionnaire, International Journal of Industrial Ergonomics 36 (2006) 141-149.

[35] J. C. de S. Van Der Linden, L. B. de M. Guimarães, R. Tabasnik, Conforto e Desconforto: são constructos opostos? In: $3^{\circ}$. Congresso Internacional de Pesquisa em Design; 2005; Rio de Janeiro: RJ; 2005.

[36]P. Vink, M. P. Looze and L. F. M. Kuijt-Evers, Theory of Comfort, in: P. Vink, Comfort and Design: Principles and Good Practice, CRC PRESS, London, 2004, pp.13-32.

[37]P. Vink, C. J. Overbeeke and P. M. A. Desmet, Comfort Experience, in: P. Vink, Comfort and Design: Principles and Good Practice. CRC PRESS, London, 2004, pp. 1-12.

[38] L. Zhang, M. G. Helander and C. G. Drury, Identifying factors of comfort and discomfort in sitting, Human Factors 38 (1996) 377-389. 